Supplement of Biogeosciences, 17, 6357-6375, 2020 https://doi.org/10.5194/bg-17-6357-2020-supplement (C) Author(s) 2020. This work is distributed under the Creative Commons Attribution 4.0 License.

(c) (1)

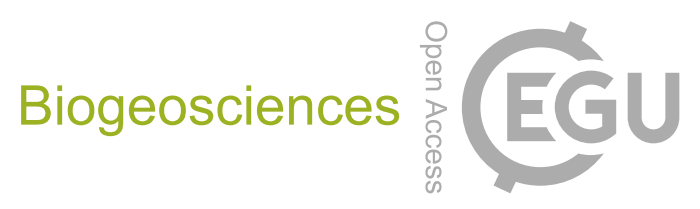

Supplement of

\title{
Reduced growth with increased quotas of particulate organic and inor- ganic carbon in the coccolithophore Emiliania huxleyi under future ocean climate change conditions
}

Yong Zhang et al.

Correspondence to: Kunshan Gao (ksgao@xmu.edu.cn)

The copyright of individual parts of the supplement might differ from the CC BY 4.0 License. 


\section{Supplemental Information}

Table S1. Average surface seawater $p \mathrm{CO}_{2}$ level ( $\mu$ atm), sea surface temperature $\left({ }^{\circ} \mathrm{C}\right)$, daytime mean irradiance $\left(\mu \mathrm{mol}\right.$ photons $\left.\mathrm{m}^{-2} \mathrm{~s}^{-1}\right)$, and nutrient concentration $\left(\mu \mathrm{mol} \mathrm{L}^{-1}\right)$ during 2000 to 2007 in Norwegian coastal waters where the E. huxleyi strain used here was isolated from (Larsen et al., 2004; Locarnini et al., 2006; Omar et al., 2010), and in projected levels for 2100 in high-latitude province in North Atlantic Ocean (Future) (Boyd et al., 2015).

\begin{tabular}{llllll}
\hline $\begin{array}{l}p \mathrm{CO}_{2} \\
(\mu \mathrm{atm})\end{array}$ & $\begin{array}{l}\text { Temperature } \\
\left({ }^{\circ} \mathrm{C}\right)\end{array}$ & $\begin{array}{l}\text { Daily irradiance } \\
\left(\mu \mathrm{mol} \text { photons } \mathrm{m}^{-2} \mathrm{~s}^{-1}\right)\end{array}$ & $\begin{array}{l}\text { Nitrate } \\
\left(\mu \mathrm{mol} \mathrm{L}^{-1}\right)\end{array}$ & $\begin{array}{l}\text { Phosphate } \\
\left(\mu \mathrm{mol} \mathrm{L}^{-1}\right)\end{array}$ \\
\hline $2000-$ & $240-400$ & $6.0-16.0$ & $120-350$ & $0-7.0$ & $0.1-0.5$ \\
2007 & & & & & \\
Future & $580-970$ & $7.9-19.0$ & $156-455$ & $0-4.9$ & $0.1-0.3$ \\
\hline
\end{tabular}


Table S2. Comparison of experiment treatments between the studies of Zhang et al. (2019) and this work. Main differences between two studies were marked in bold.

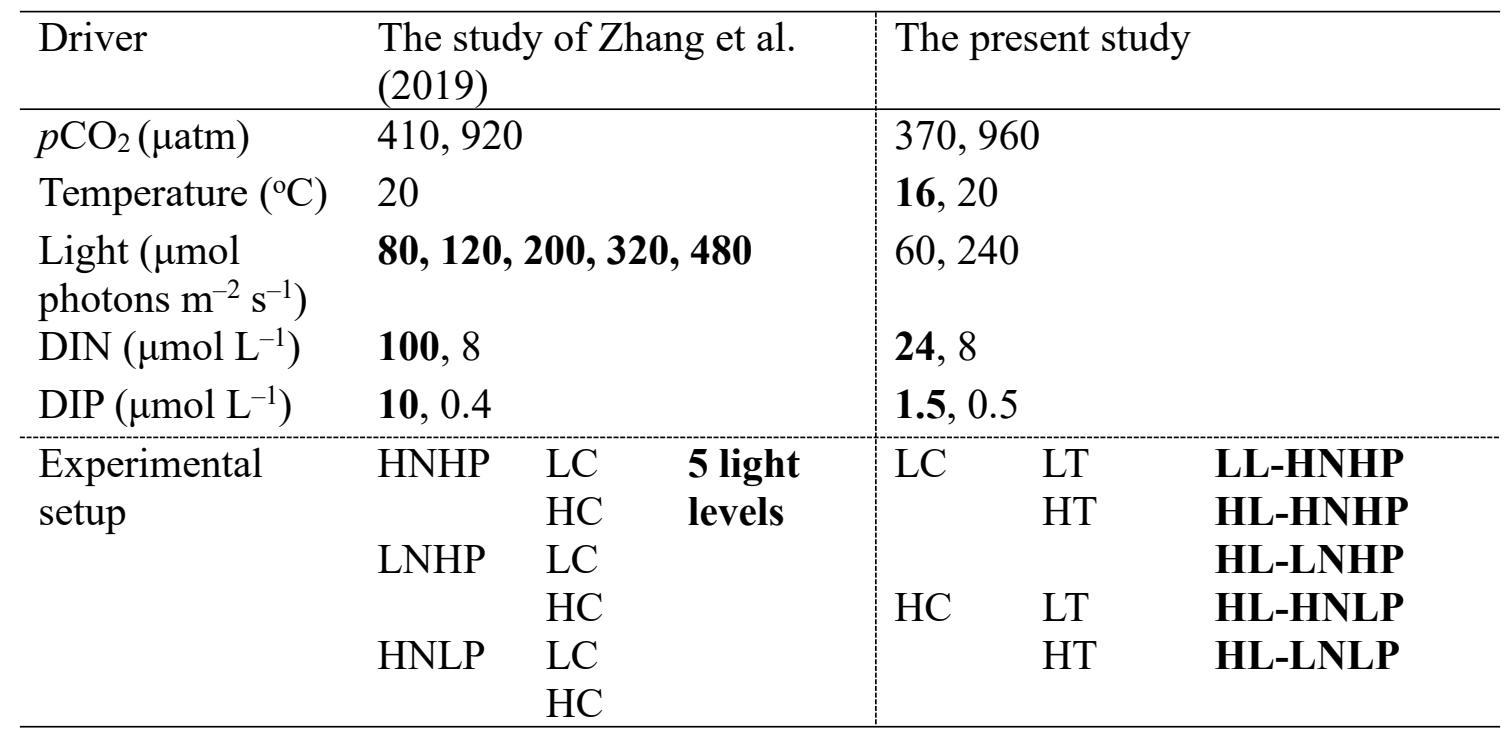


(a)
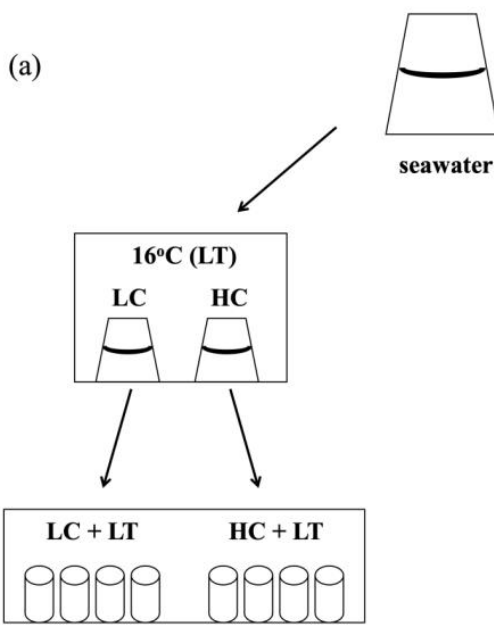

$310 \mathrm{ml}$ seawater
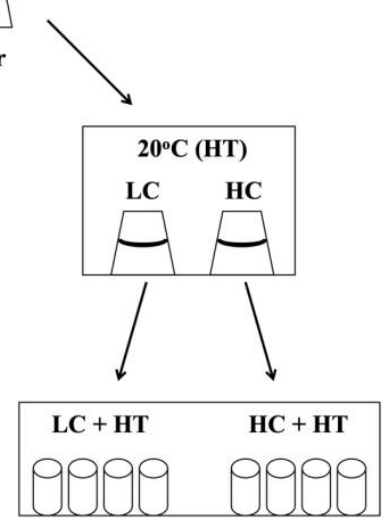

$310 \mathrm{ml}$ seawater

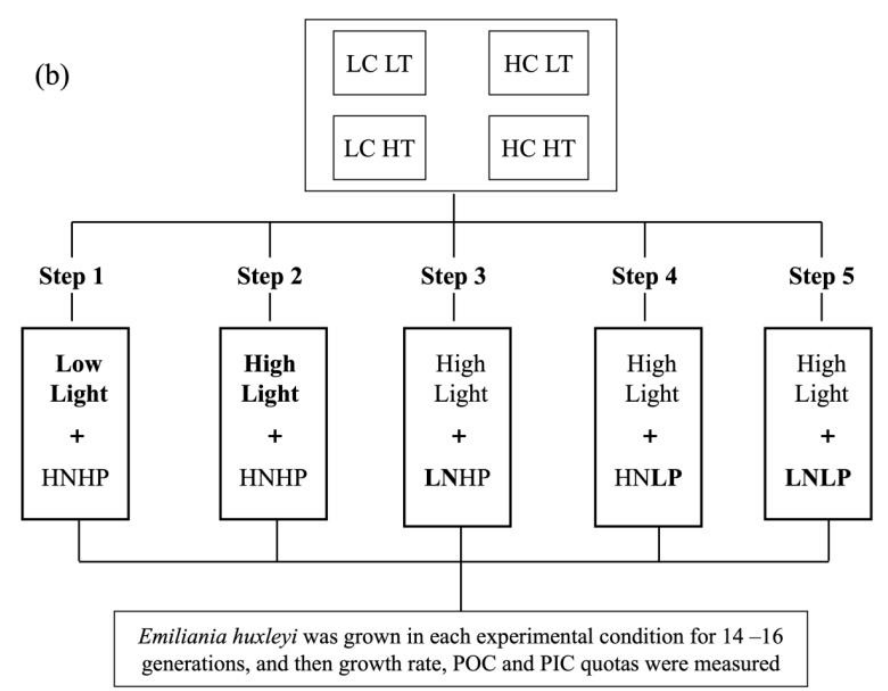

Figure S1. Flow chart of the experimental processes. Experimental steps were done in a consecutive manner. Detailed experimental conditions were shown in Figure 1. 

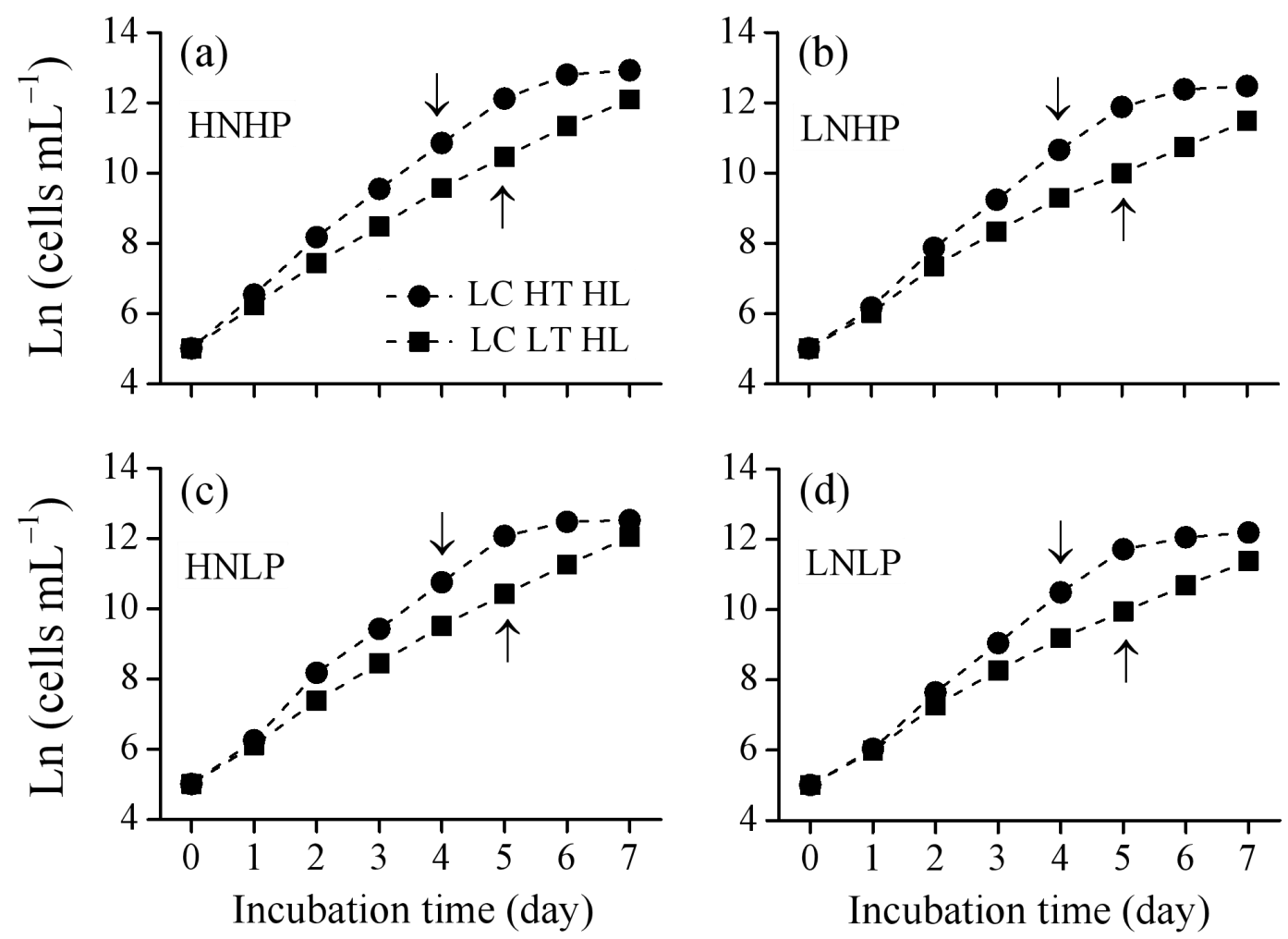

Figure S2. Representative curves for the time course for cell concentrations of $E$. huxleyi under low $p \mathrm{CO}_{2}$ (LC), high (HT) or low (LT) temperatures, and high light (HL) conditions with varying levels of nutrients: HNHP (a), LNHP (b), HNLP (c) and LNLP (d), respectively. Arrow indicates the day when samples were taken in each treatment. Data were means \pm sd of 4 replicate populations. Detailed experimental conditions were shown in Figure 1. 

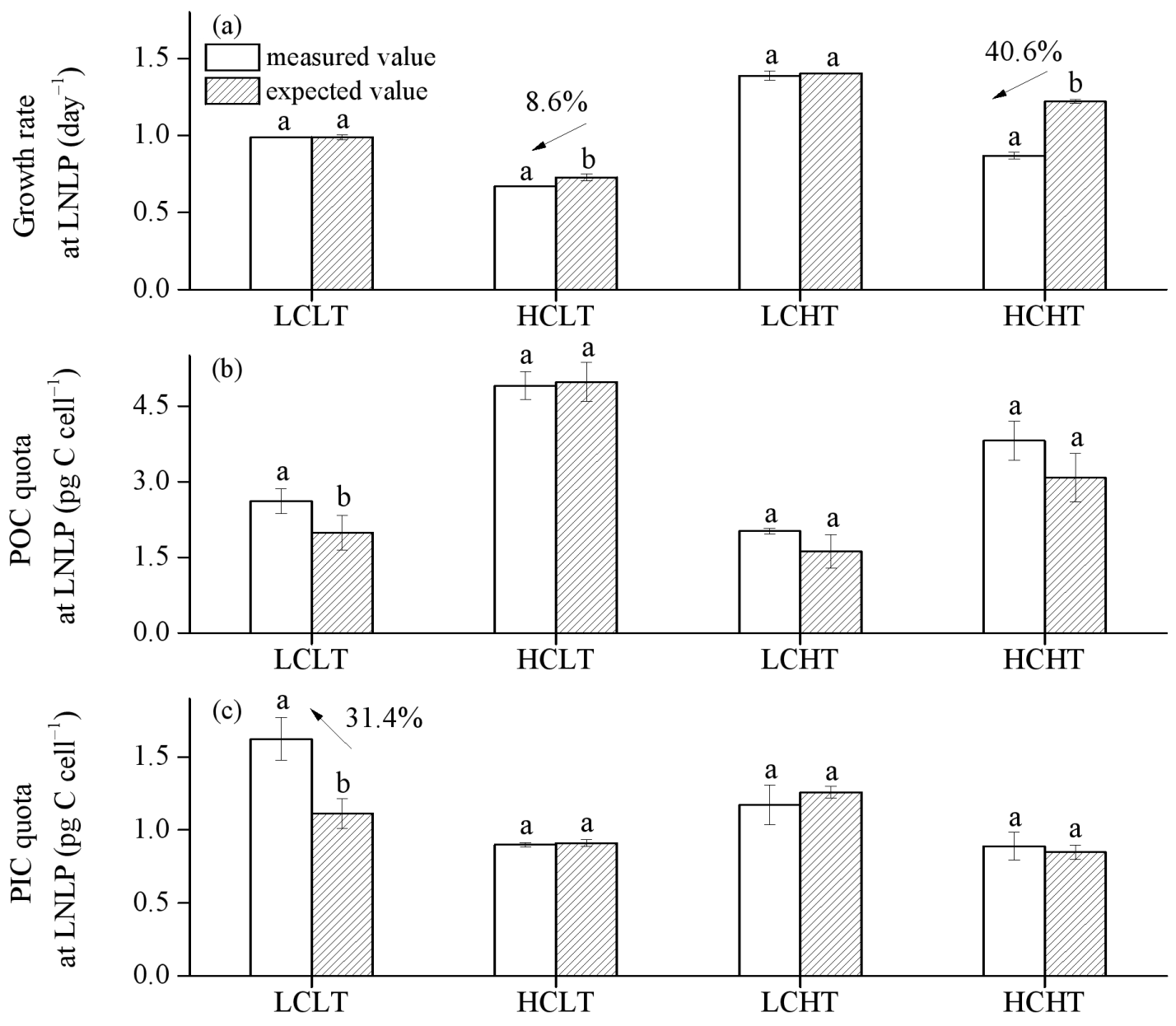

Figure S3. Comparison of growth rate (a), POC quota (b) and PIC quota (c) between the expected (calculated) values and the measured values under the LNLP treatments. Different letters $(\mathrm{a}, \mathrm{b})$ in each "baseline" environment (LCLT, HCLT, LCHT or HCHT) represent significant differences (Tukey Post hoc, $p<0.05$ ). Detailed experimental conditions were shown in Figure 1. 


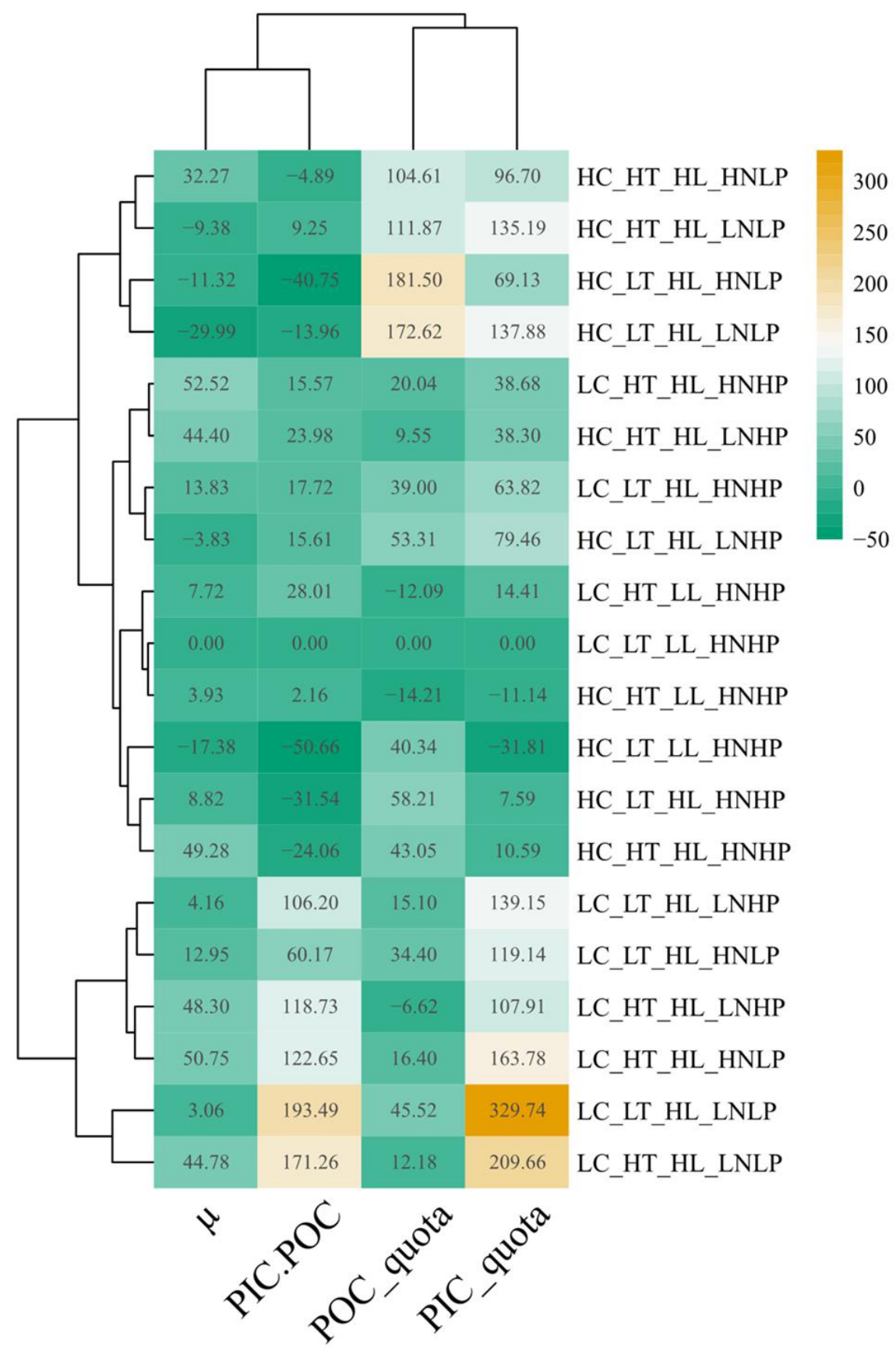

Figure S4. Heatmap of the changes in growth rate, POC quota, PIC quota and PIC:POC in each treatment. Values in the present scenario (LC LT LL HNHP) were considered as the control. A minus sign indicates the reduction in these parameters. 

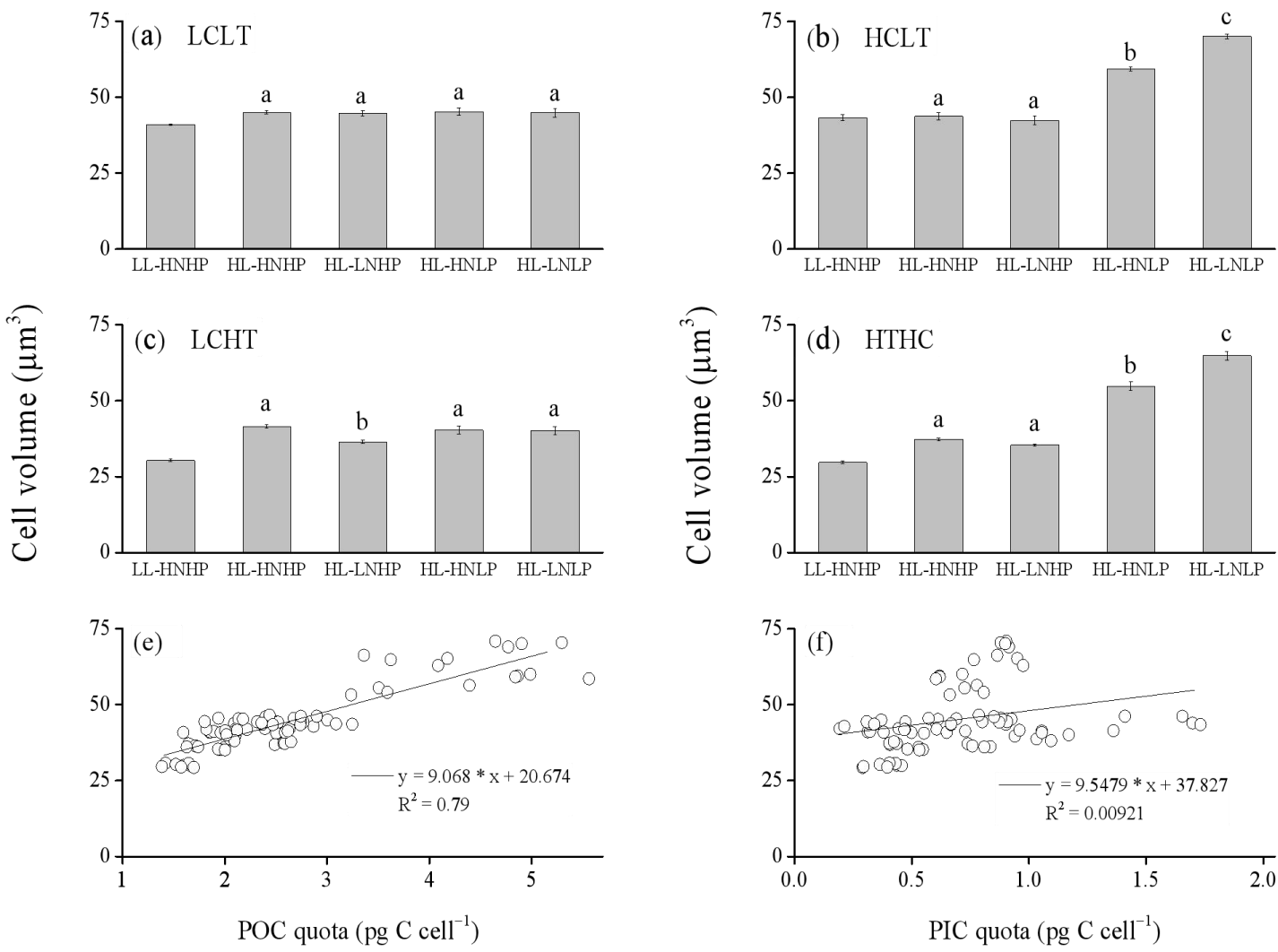

Figure S5. Cell volume of E. huxleyi grown in LCLT (a), HCLT (b), LCHT (c) and HCHT (d) conditions, and its correlation with POC quota (e) and PIC quota (f). Data were obtained after cells were acclimated to experimental conditions for 14-16 generations and means $\pm \mathrm{sd}$ of 4 replicate populations in panels (a)-(d). Each point in panels (e) and (f) indicates an individual replicate from all experiment. Different letters $(a, b, c)$ in panels $(\mathbf{a})-(\mathbf{d})$ represent significant differences between different nutrient treatments (Tukey Post hoc, $p<0.05$ ). 


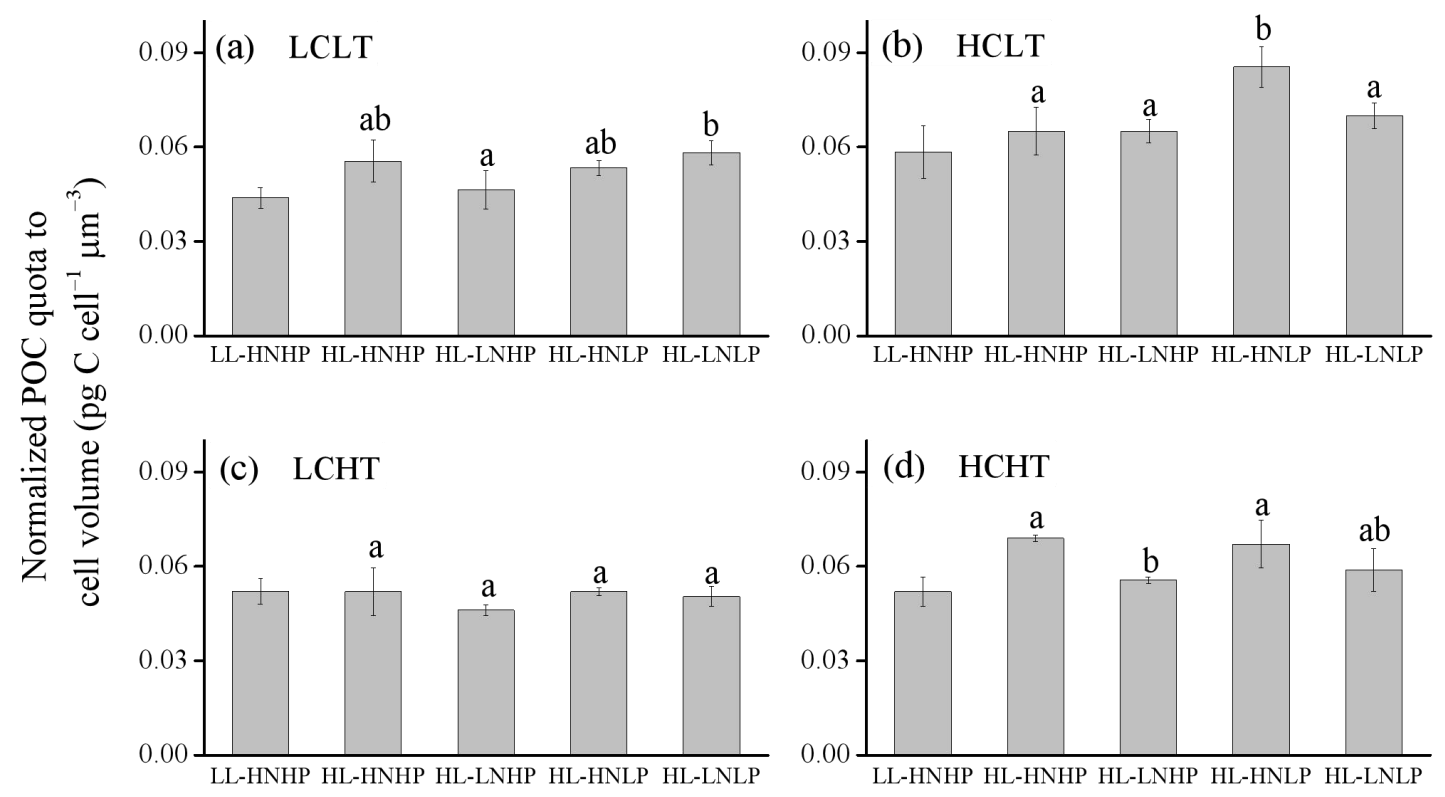

Figure S6. Normalized POC quota of E. huxleyi to cell volume in LCLT (a), HCLT (b), LCHT (c) and HCHT (d) conditions. Data were obtained after cells were acclimated to experimental conditions for 14-16 generations and means \pm sd of 4 replicate populations. Different letters $(a, b)$ in each panel represent significant differences between different nutrient treatments (Tukey Post hoc, $p<0.05$ ). 

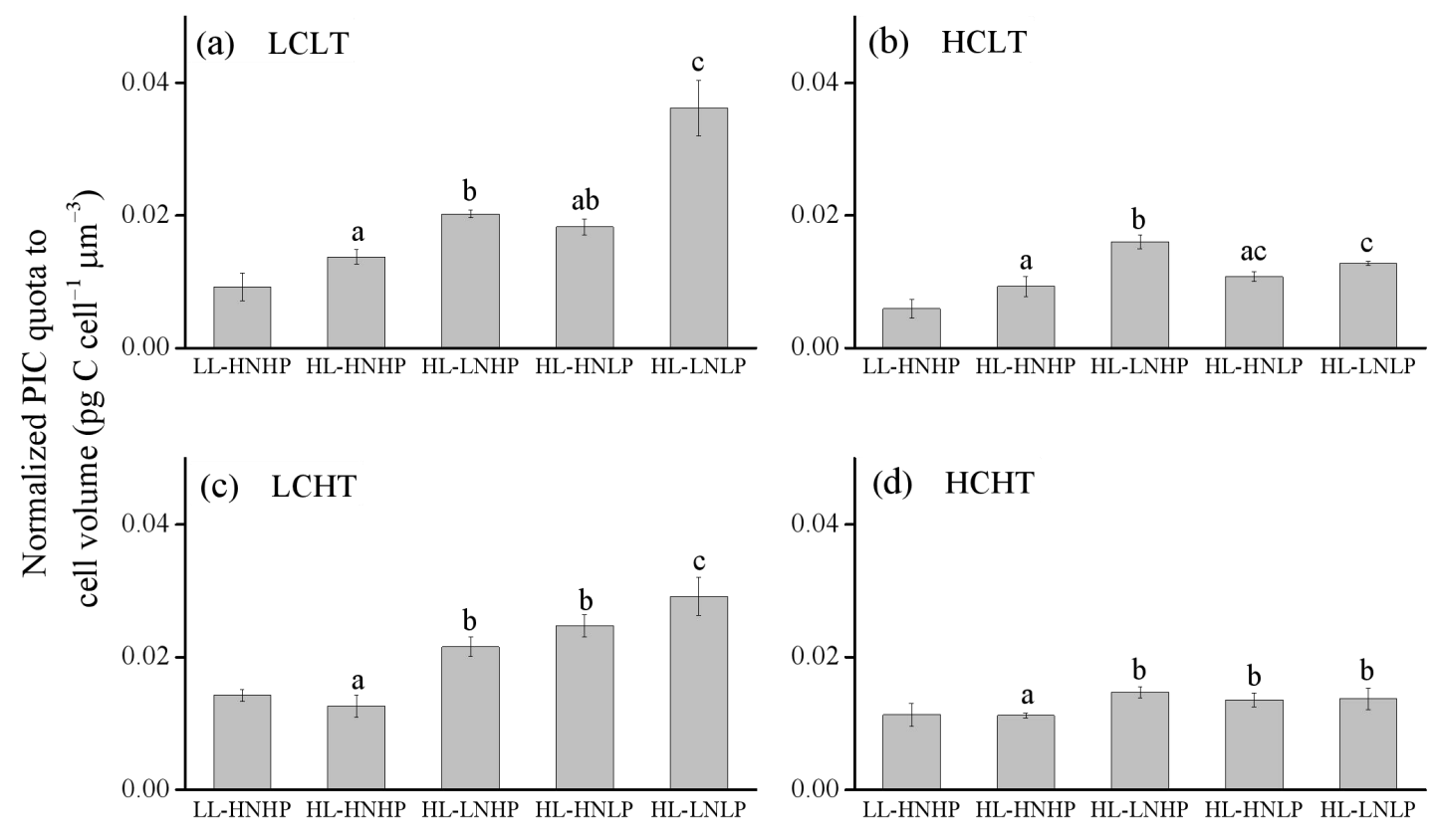

Figure S7. Normalized PIC quota of E. huxleyi to cell volume in LCLT (a), HCLT (b), LCHT (c) and HCHT (d) conditions. Data were obtained after cells were acclimated to experimental conditions for 14-16 generations and means \pm sd of 4 replicate populations. Different letters $(a, b, c)$ in each panel represent significant differences between different nutrient treatments (Tukey Post hoc, $p<0.05$ ). 

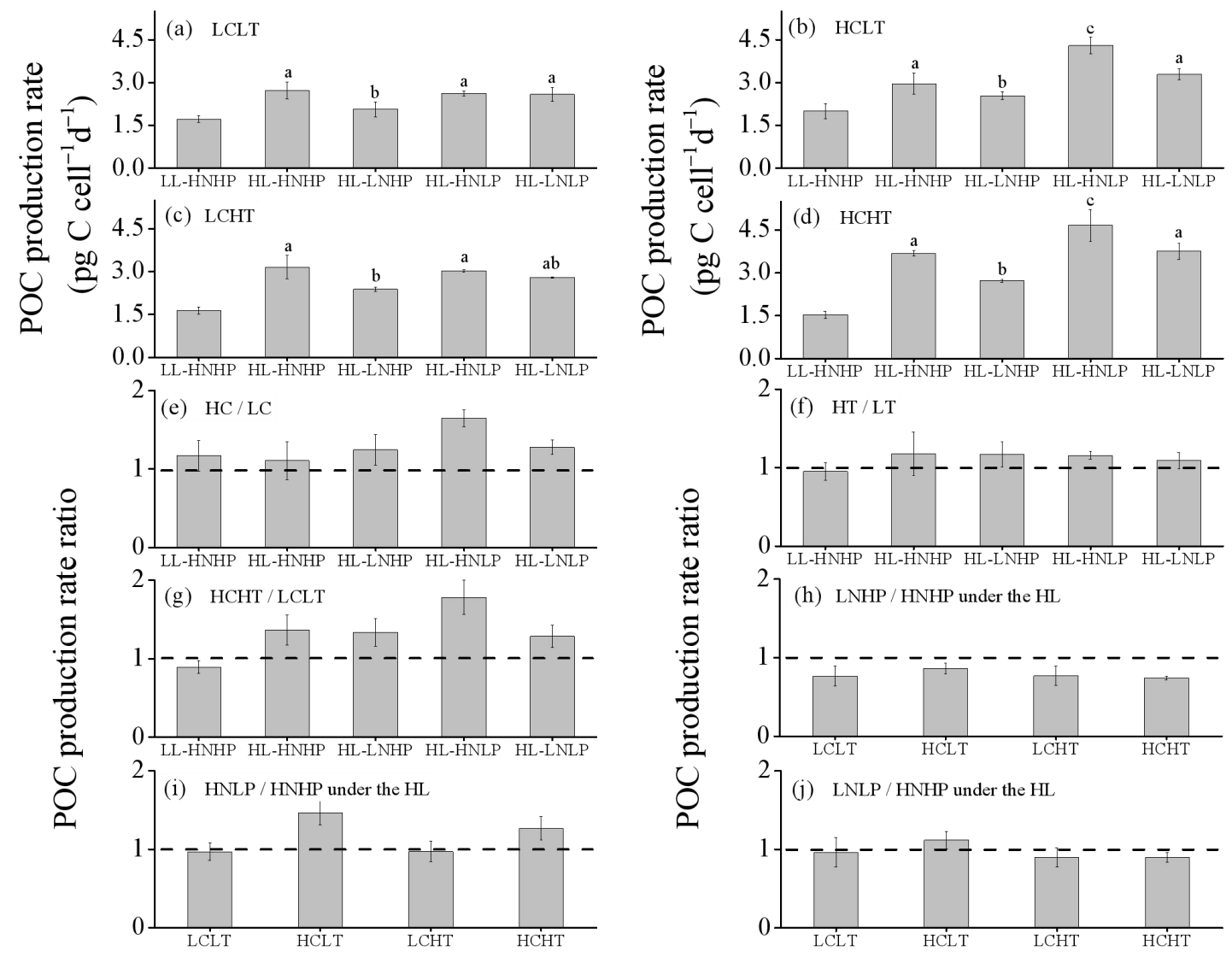

Figure S8. POC production rate of E. huxleyi in LCLT (a), HCLT (b), LCHT (c) and HCHT (d) conditions, and the ratio of POC production rate at $\mathrm{HC}$ to LC (e), HT to LT (f), HCHT to LCLT (g), LNHP to HNHP (h), HNLP to HNHP (i) and LNLP to HNHP (j). Data were obtained after cells were acclimated to experimental conditions for $14-16$ generations and means \pm sd of 4 replicate populations. Horizontal lines in panels (e)-(j) showed the value of 1. Different letters $(a, b, c)$ in panels (a)-(d) represent significant differences between different nutrient treatments (Tukey Post hoc, $p<0.05)$. 

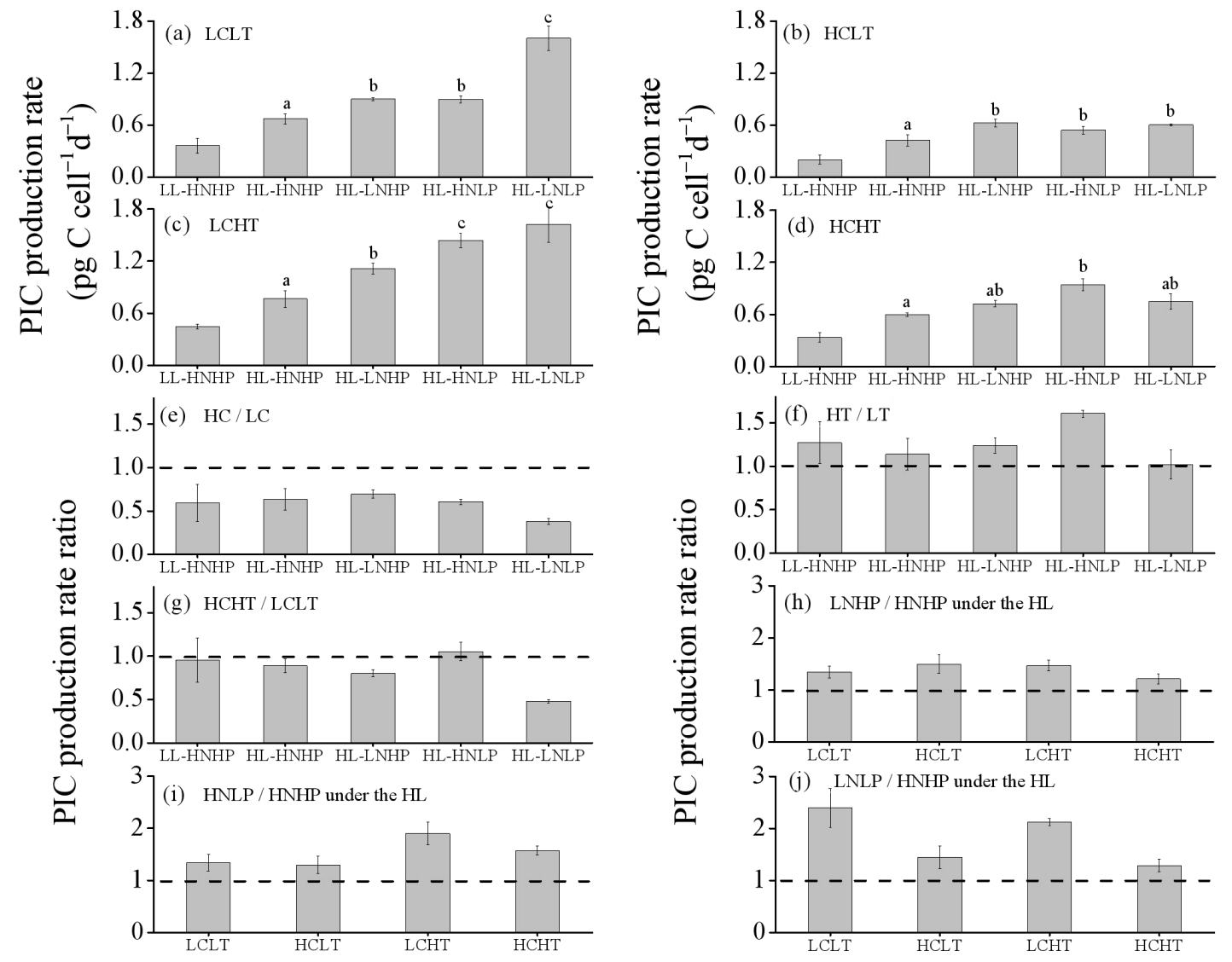

Figure S9. PIC production rate of E. huxleyi in LCLT (a), HCLT (b), LCHT (c) and HCHT (d) conditions, and the ratio of PIC production rate at HC to LC (e), HT to LT (f), HCHT to LCLT (g), LNHP to HNHP (h), HNLP to HNHP (i) and LNLP to HNHP (j). Data were obtained after cells were acclimated to experimental conditions for 14-16 generations and means \pm sd of 4 replicate populations. Horizontal lines in panels (e)-(j) showed the value of 1. Different letters $(a, b, c)$ in panels (a)-(d) represent significant differences between different nutrient treatments (Tukey Post hoc, $p<0.05)$. 

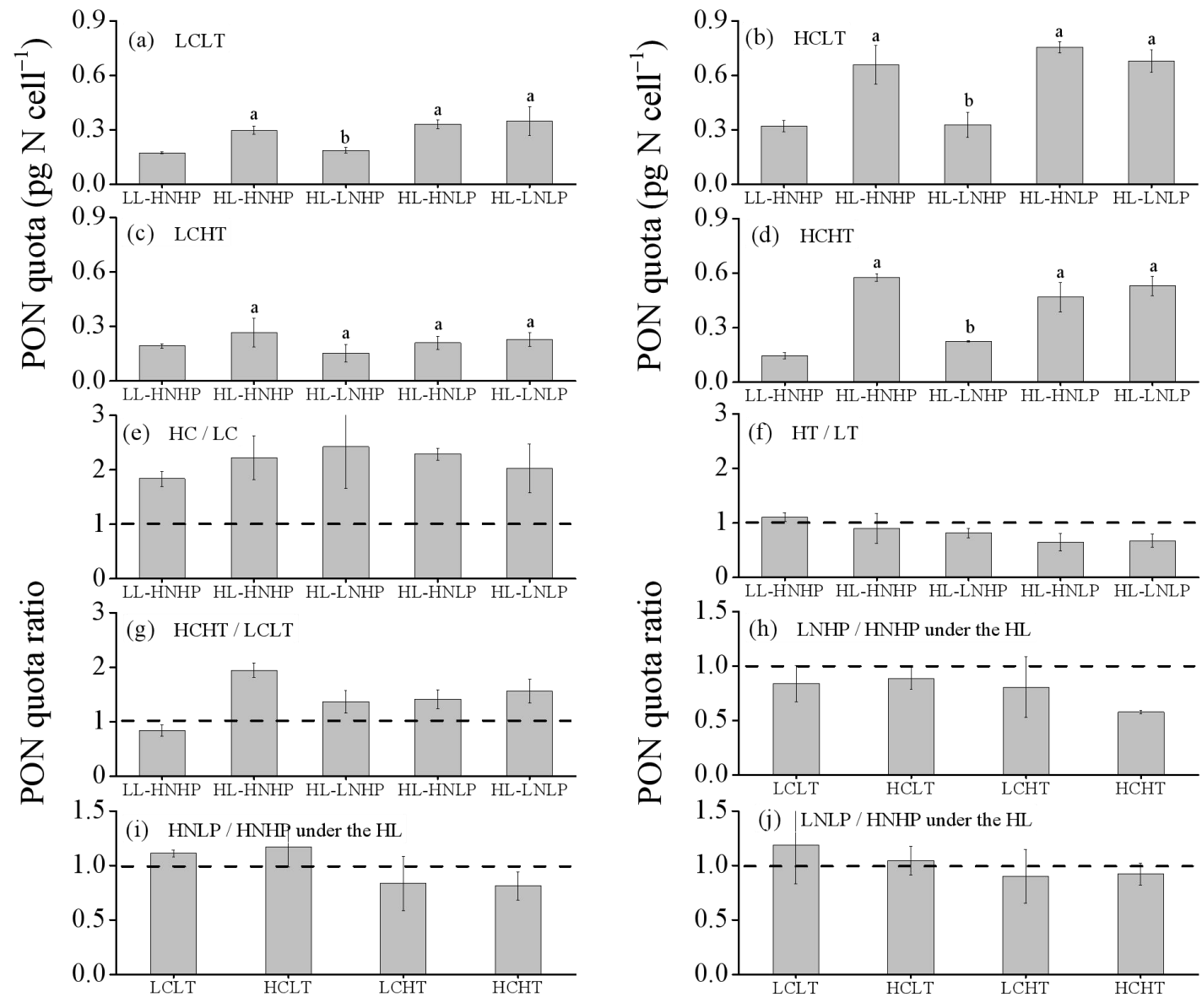

Figure S10. PON quota of E. huxleyi in LCLT (a), HCLT (b), LCHT (c) and HCHT (d) conditions, and the ratio of PON quota at $\mathrm{HC}$ to LC (e), HT to LT (f), HCHT to LCLT (g), LNHP to HNHP (h), HNLP to HNHP (i) and LNLP to HNHP (j). Data were obtained after cells were acclimated to experimental conditions for 14-16 generations and means \pm sd of 4 replicate populations. Horizontal lines in panels (e)(j) showed the value of 1. Different letters $(a, b)$ in panels (a)-(d) represent significant differences between different nutrient treatments (Tukey Post hoc, $p<0.05$ ). 


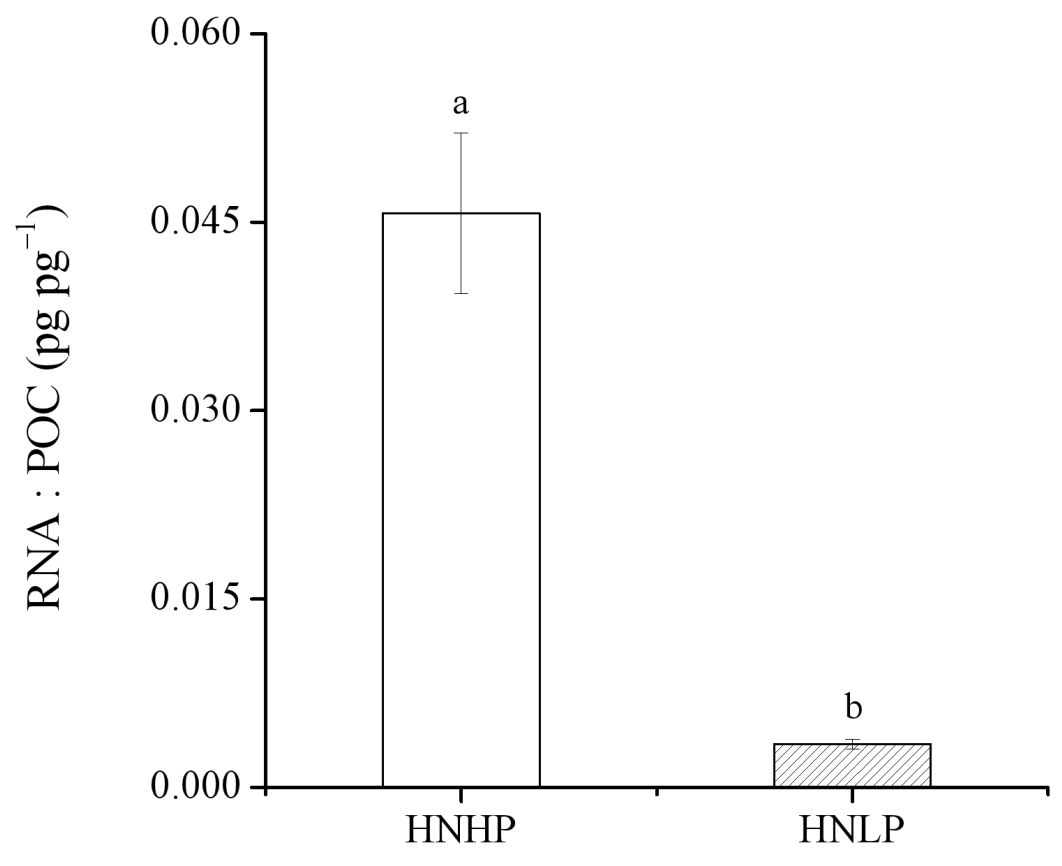

Figure S11. Normalized RNA quota of E. huxleyi to POC quota in HNHP and HNLP conditions. Data were obtained after cells were acclimated to experimental conditions for 14-16 generations and means \pm sd of 4 replicate populations. Different letters $(a, b)$ represent significant differences between different nutrient treatments (Tukey Post hoc, $p<0.05)$. 


\section{References}

Boyd, P. W., Lennartz, S. T., Glover, D. M., and Doney, S. C.: Biological ramifications of climate-change-mediated oceanic multi-stressors, Nat. Clim. Change, 5, 71-79, doi: 10.1038/nclimate2441, 2015.

Larsen, A., Flaten, G. A. F., Sandaa, R., Castberg, T., Thyrhaug, R., Erga, S. R., Jacquet, S., and Bratbak, G.: Spring phytoplankton bloom dynamics in Norwegian coastal waters: Microbial community succession and diversity, Limnol. Oceanogr., 49, 180-190, doi: 10.4319/1o.2004.49.1.0180, 2004.

Locarnini, R. A., Mishonov, A. V., Antonov, J. I., Boyer, T. P., and Garcia, H. E.: World ocean atlas 2005, V. 1: Temperature, edited by: Levitus, S., NOAA Atlas NESDIS 61. U. S. Government Printing Office, 123-134, 2006.

Omar, A. M., Olsen, A., Johannessen, T., Hoppema, M., Thomas, H., and Borges, A. V.: Spatiotemporal variations of $f \mathrm{CO}_{2}$ in the North Sea, Ocean Sci., 6, 77-89, doi: 10.5194/osd-6-1655-2009, 2010.

Zhang, Y., Fu, F., Hutchins, D. A., and Gao. K.: Combined effects of $\mathrm{CO}_{2}$ level, light intensity and nutrient availability on the coccolithophore Emiliania huxleyi, Hydrobiologia, 842, 127-141, doi: 10.1007/s10750-019-04031-0, 2019. 